\title{
Televisão Digital Interativa e o uso da Tipografia com liberdade: fatores morfológicos e técnicos determinantes da legibilidade e leiturabilidade.
}

Interactive Digital Television and the use of typography with freedom: morphological

and technical determinants of legibility and readability factors.

\author{
> Karine Itao Palos \\ Universidade Anhembi Morumbi, Brasil \\ karineipa@hotmail.com
}

\author{
$>$ José Neto de Faria \\ Universidade Anhembi Morumbi, Brasil \\ josenetodesign@yahoo.com.br
}

\begin{abstract}
This project involves a study of typographic morphologies, along with a technical description and analysis of programs and devices that make up the Digital Interactive Television, with the objective to outline the characteristics of the types that work best on it to qualify its interfaces, which will then enable better understanding and assimilation of content, this way it was found that the one area of typography provides freedom in the construction of the content, but these qualities vary according to the technological qualities and social contexts of devices.
\end{abstract}

Keywords: Digital Interactive Television; Design; Typography; Legibility and Readability; and Interface.

\section{Introdução}

O presente trabalho propóe um estudo das características técnicas e morfológicas das tipografias, dos programas e do conjunto de dispositivos que compóe a Televisão Digital Interativa - TVDi, a fim de descrever os melhores modos de adequaçáo da tipografia para qualificar as interfaces desse meio, com o intuito de permitir que o 'Indutor de Atividade' (Miranda,1998) assimile de forma natural os conteúdos exibidos.

\section{Metodologia}

Os procedimentos metodológicos adotados no projeto visam: descrever as características morfológicas das tipografias; descrever as características técnicas dos dispositivos que compóe a TVDi, primeira e segunda tela; descrever como as tipografias são utilizadas nas interfaces dos programas desenvolvidos para a TVDi; descrever o comportamento do 'Indutor de Atividade' quando confrontado com as distintas morfologias tipográficas; descrição de parâmetros para o desenvolvimento de programas e aplicativos; e por fim, análise, verificação e descrição dos resultados.

\section{Televisão Digital Interativa - TVDi}

Assim como no meio impresso em que se deve ter em mente que cada família tipográfica pode se tornar boa ou ruim, dependendo da plataforma e do contexto de uso que é aplicada (Lupton, 2006, p.37), no meio digital essas perspectivas ainda são válidas, no caso da Televisão Interativa há a possibilidade de se trabalhar com diversos dispositivos, os quais apresentam diferentes especificidades, as quais podem exigir demandas tipográficas distintas. Dessa forma, é importante entender um pouco das especificidades do suporte da TVDi: incontestavelmente o principal dispositivo trabalhado nesse meio é a Televisão também chamada de primeira tela, que é responsável pelas exibiçôes dos programas e pode possuir alguns recursos interativos, acrescentar informaçóes ou promover personalizaçóes que ajudem a complementar o conteúdo que está sendo exibido, mas é uma interface mais dura, com interaçóes menos intuitivas e naturais.

Grande parte dos conteúdos de caráter visual são disponibilizados para a primeira tela (Fig1), vídeos, imagens, textos, mas a televisão não é uma plataforma recente, dessa maneira deve-se entender que esse tipo de equipamento existe ainda em diferentes graus tecnológicos nos lares do 'Indutor de Atividade'. Equipamentos antigos podem ser adaptados, para receber o chamado sinal digital que melhora consideravelmente a qualidade da imagem, o que permite processos interativos (Fig.2). Mas apesar de poderem ser acessadas as interatividades na televisão analógica, a imagem não é tão nítida como a de televisores HD.

A adaptação do sinal digital para os televisores analógicos é feita através de um equipamento conhecido como Set-Top Box - STB (Veiga, 2006, p.24), que pode ser classificado em três categorias: Broadcast TV esse modelo não permite a utilização do canal de retorno, ou seja ele só pode dar acesso a algumas interaçóes locais, sem envio de dados para a emissora; o Enhanced $T V$ neste o canal de retorno está presente, o que significa que é possível o envio de dados para a emissora; o último modelo é o Advanced Services que permite troca de dados em tempo real ampliando as capacidades interativas. 


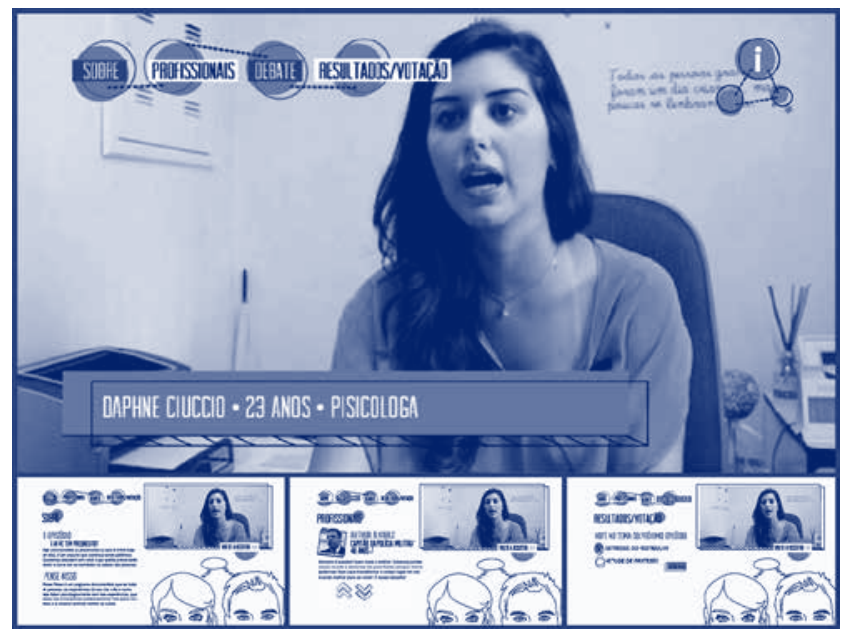

Figura 1: Primeira tela do programa piloto: "Pense Nisso" (Ciuccio; Damacena; Junior; Leal; Palos; Santos; Scholz; Watanabe, 2013).

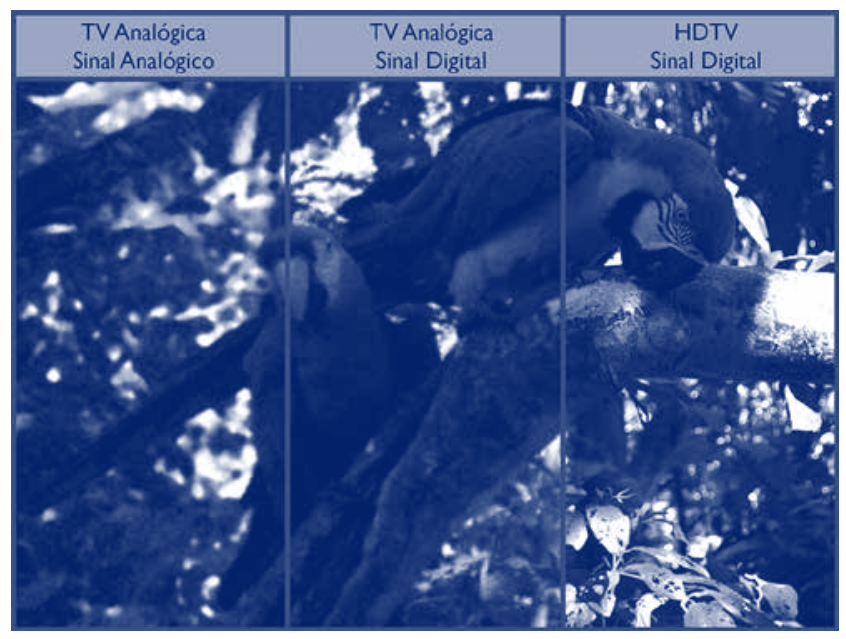

Figura 2: Diferenças de qualidade de imagem entre a televisão analógica, analógica emulando o sinal digital e HD.

Nesse contexto, além da qualidade de imagem que pode interferir em como o 'Indutor de Atividade' perceberá a informação devido à legibilidade da tipografia, há mais um fator referente à primeira tela que pode impactar na qualidade das percepçôes dos conteúdos: o ambiente externo que também interfere no andamento do programa, pois o 'Indutor de Atividade' sempre está sujeito a essas interferências externas, ou seja, sáo as atividades que estáo acontecendo ao seu redor e também interferem na forma de como se percebe o conteúdo, essas interferências podem ser causadas tanto pelo fato de a televisão ser uma atividade a ser contemplada em grupo quanto pelo fato de que o contexto de uso de uma TV é mais relaxado do que em um computador.

Outro dispositivo que contempla a televisão digital interativa é a segunda tela, que contempla o Mobile (Fig.3) principalmente em Tablets ou Smartphones que possuem recursos de caráter mais interativo mais natural, que podem ser manipulados com o uso do

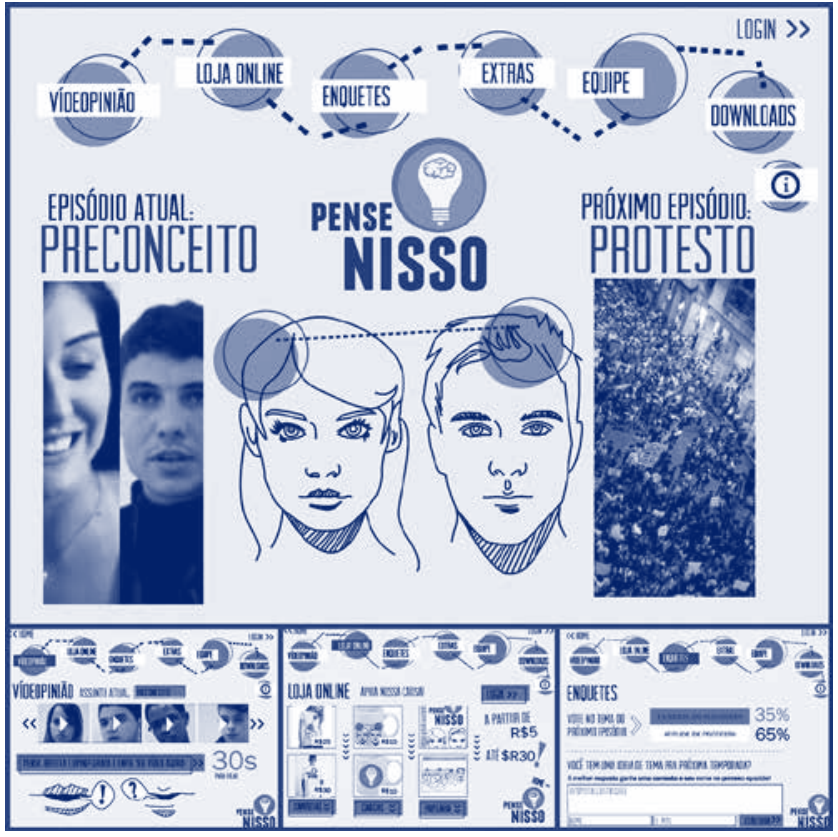

Figura 3: Segunda tela do programa piloto: "Pense Nisso" (Ciuccio; Damacena; Junior; Leal; Palos; Santos; Scholz; Watanabe, 2013).

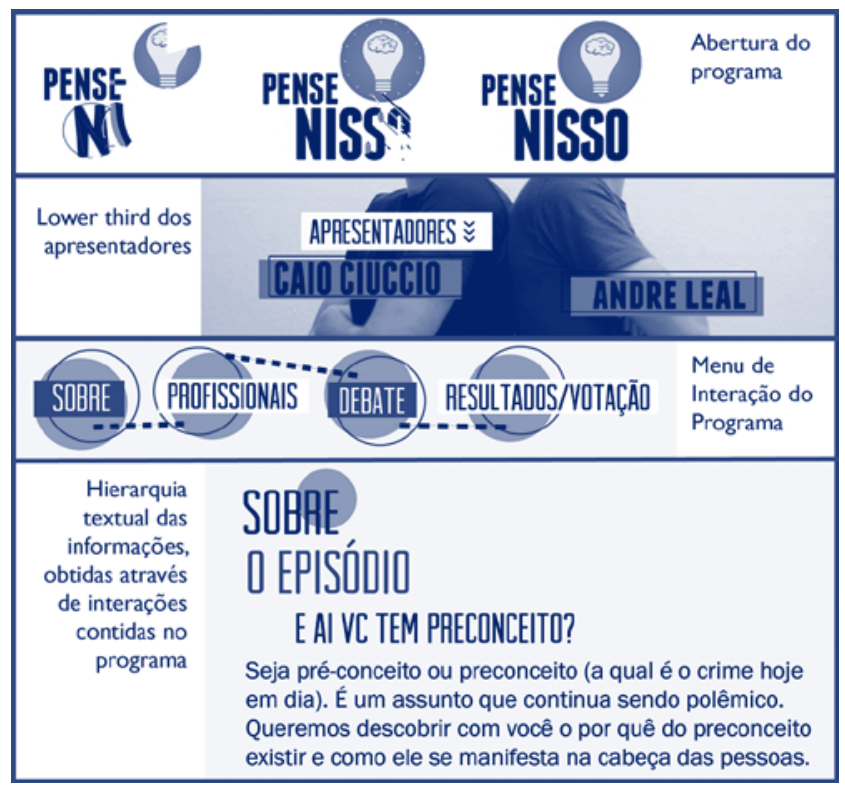

Figura 4: Aplicação da Tipografia na primeira tela, programa piloto: "Pense Nisso" (Ciuccio; Damacena; Junior; Leal; Palos; Santos; Scholz; Watanabe, 2013).

deslizar dos dedos sobre a tela, os recursos existentes são conteúdos extras, vídeo, jogos e informaçóes que possibilitam ampliar a percepçôes sobre o assunto exibido na primeira tela.

\section{Tipografia}

ATVDi conta com diversos dispositivos que auxiliam na promoção de interaçóes com o público, entre eles: a primeira e segunda tela, essas duas plataformas apresentam contextos de uso distintos o que 


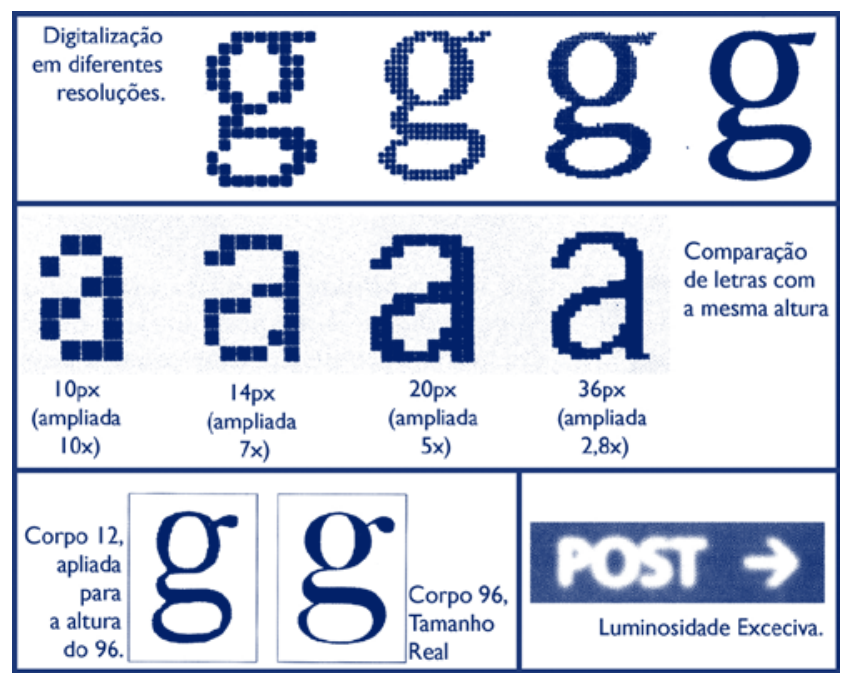

Figura 5: Comparação de amostras de tipografia, e possíveis efeitos descritos acima (Pereira, 2007, p.67, 78, 79, 87).

impacta em como as composiçôes, as interações e as informaçóes serão trabalhados, e por fim quais características são melhor aplicadas em cada um dos contextos descritos abaixo.

Na primeira tela (Fig.4), os usos mais comuns da tipografia são relativos à macro e a micro, a macro tipografia usadas em títulos e chamadas que possuem um maior apelo visual, uma vez que sua função é chamar a atenção para as atraçóes exibidas, por isso pode conter mais detalhes, serifas, os espaçamentos geralmente já são adaptados ao contexto, o tamanho geralmente é bem maior do que os encontrados em outros textos, a micro tipografia é aplicada em textos informativos, botóes, é uma tipografia mais simples, com menos detalhes, utilizada para transmitir as informaçóes mais vigorosas. Os conteúdos são exibidos em televisores que estáo posicionados a uma distância relativamente grande do 'Indutor de Atividade', isso impacta de diferentes formas na tipografia, primeiramente o tamanho, que tem que ser maior do que em um Tablet, o que ocasiona na escolha de uma fonte que possa se adaptar a essa condiçáo ou que seja pensada para ser aplica em um tamanho grande, superior a 18px (BBC, 2006), a escolha de uma tipografia especial devido ao tamanho é consequência de que a tipografia pode ser planejada para ser melhor aplicada em dimensóes grandes (Lupton, 2006 p.34-37; Pereira 2007 p.77-78), um exemplo disso são as correçóes com relaçáo à espessura, engrossando ou afinando, para dar melhor visibilidade ao tipo (Hochuli, 2013, p.10-23) (Fig.5). Outra questáo são os espaçamentos, tanto o kerning, espaçamento entre letras, como as entrelinhas devem ser aumentados (Spiekermann, 2011, p.93), esse aumento é devido tanto à distância do 'Indutor de Atividades' como por se tratar de um meio digital, que é óptico e se utiliza de luz para formar as imagens que incidem diretamente sobre os olhos, interferindo na legibilidade dos caracteres (Pereira, 2007, p.86). Tipos muito finos, serifados ou com muitos detalhes não devem ser usados para esse tipo de mídia (BBC, 2006), já que esses detalhes se transformam em ruídos visuais o que dificulta a leitura. No cenário digital a leitura geralmente é mais lenta, o

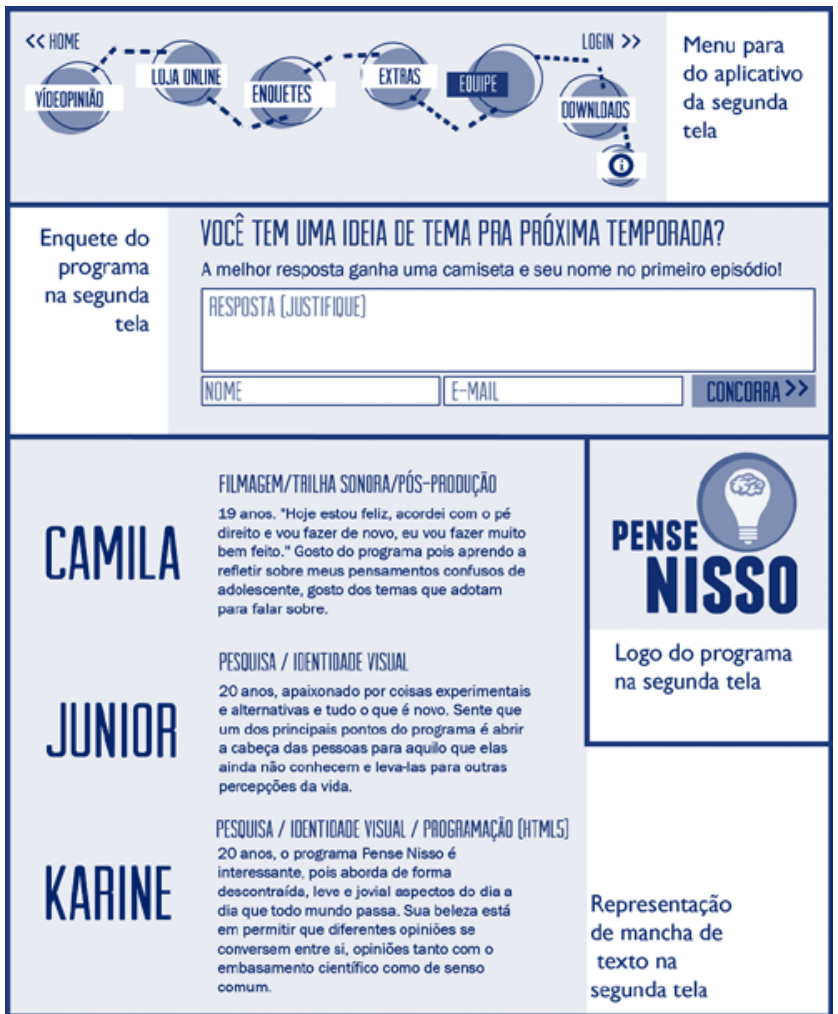

Figura 6: Aplicação da tipografia na segunda tela, programa piloto: "Pense Nisso" (Ciuccio; Damacena; Junior; Leal; Palos; Santos; Scholz; Watanabe, 2013).

contexto ambiental da televisão é mais relaxado e o 'Indutor de Atividade' se encontra envolvido por diversos estímulos visuais e auditivos, dessa forma o conteúdo veiculado deve-se apresentar de forma objetiva, breve e diluída dentro do programa. Da primeira tela, poderia se esperar que tivesse um atrativo interativo, mas por razôes muitas vezes tecnológicas a maioria das televisóes conta apenas com o controle remoto para realizar as interaçóes, essa é uma interface pouco intuitiva e pouco natural que náo facilita as interaçóes entre o 'Indutor de Atividade' e a TV.

A segunda tela é composta pelos mobiles, Tablets e Smartphones, Os smartphones são soluções igualmente possíveis, mas representam um dispositivo com tamanho diferente, devem ser estudados de forma separada e não serão contemplados nesse artigo. Comparando com a Televisão, os Tablets estão próximos ao 'Indutor de Atividade' (Cardoso, 2013, p.01-07), permitindo o uso de fontes que sejam relativamente menores e mais delicadas (Fig.6), assim como na primeira tela, deve-se escolher um tipo ideal para essa característica. Há tipos construídos para funcionar bem tanto em tamanhos grandes, quanto tamanhos pequenos, esses tipos podem se ajustar de acordo com as dimensóes desejadas, o kerning aplicado pode ser ligeiramente maior do que o das mídias impressas, pois facilita a leitura à entrelinha (Spiekermann, 2011, p.93), também deve ser mais espaçosa, no entanto tanto na primeira como na segunda tela, esse espaço não deve ser grande a ponto de causar deformidade nas manchas de texto o que causaria uma dificuldade de unificaçáo do texto, deve-se usar preferencialmente 
fontes sans-serifa (Pereira, 2007, p.87). Apesar de dispor de mais espaço para veicular informaçóes textuais, os textos devem ser aplicados de forma breve e objetiva, fazendo da animação e das possibilidades de interação veículo para estimular o entendimento do assunto. Na TVDI as interaçóes que necessitam que o 'Indutor de Atividade' digite algum dado precisam ser feitas através da segunda tela, pois o trabalho digitar essas informaçóes através do controle remoto se torna muito ardo.

\section{Aplicação Tipográfica}

Informaçóes exibidas tanto na primeira tela quanto na segunda devem conter uma hierarquia informacional que permita facilitar a localização do 'Indutor de Atividade' dentro do texto (Lupton, 2006 p.128-139), desta forma títulos e subtítulos e textos corridos devem ser empregados para auxiliar a compreensão de forma mais eficiente o assunto abordado, nesse sentido a hierarquia da informação deve ser planejada com o objetivo de guiar o olhar do leitor pela tela em segundos, logo elementos como peso das fontes, a diferença no tamanho, a posição, as formas, as quebras de linha, a cor, o contraste e as texturas (Pereira, 2007, p.135), ajudam a guiar o olhar do leitor e permitem estabelecer a hierarquia das informaçóes no layout da tela.

Como os textos aplicados na TVDI devem se curtos e objetivos permitindo que o 'Indutor de Atividade' possa extrair as informaçóes rapidamente enquanto assiste ao programa sem gerar muitas distraçóes, nesse contexto um fator escencial na TVDI é o comprimento da linha que não deve ser muito grande variando de 60 a 65 caracteres por linha, contando com os espaços, linhas mais curtas facilitam e agilizam a leitura (Spiekermann, 2011, p.93; Hochuli, 2013 p.34).

O próximo item são os tipos alinhamento, que possuem características distintas interferindo na leitura do texto (Pereira, 2007, p.128-131; Lupton, 2006 p.108 e 109), os quatro principais tipos de alinhamento são: alinhamento à esquerda, proporciona uma excelente legibilidade, já que respeita o fluxo de leitura, da direita para a esquerda, proporcionando um espacejamento regular; alinhamento à direita, esse caso pode ser um problema em textos longos, pois a irregularidade da margem dificulta encontrar a próxima linha, podendo cansar o leitor; no alinhamento centralizado as linhas seguem o mesmo eixo vertical, nesse caso deve-se evitar linhas com comprimentos muito diferenciados, por criar irregularidades nas duas margens do texto; e por ultimo o alinhamento justificado, que oferece uma aparência limpa, entretanto o texto é forçado a caber em linhas de mesma medida, o que gera vários tamanhos de espaçamento entre as palavras. Em todos os tipos de alinhamento devesse evitar os "caminhos de rato" (Hochuli, 2013, p.49) que são os espaços verticais que surgem quando espaços entre as linhas se coincidem exatamente ou quase, em várias linhas subsequentes, o que causa uma perturbação na leitura.

Talvez a característica tipográfica mais importante a ser consideradas em textos para a TVDI, seja que a fonte escolhida deve ter relação com o conteúdo e a identidade visual do programa, nesse sentido devem-se escolher tipos que tenham tanto as características que foram trabalhadas nesse texto como tenham relação com o conteúdo exibido.

\section{Legibilidade $x$ Leiturabilidade}

Quando se estuda tipografia é impossível não relacionar as características do tipo com conceitos de legibilidade (do inglês legibility) e leiturabilidade (do inglês readability) (Pereira, 2007, p.104) que podem ser facilmente confundidos, mas possuem significados distintos, o primeiro faz referências às qualidades do tipo, o que muitas vezes remete a termos como clareza e facilidade de leitura expressa pelo mesmo. O segundo termo é referente à qualidade do conforto visual que o 'Indutor de Atividade' tem ao ler aquele texto. Esses dois termos não necessariamente, se manifestam ao mesmo tempo, nesse sentido o ideal mesmo para uma tipografia exibida na TVDI é que ela contemple esses dois conceitos para que ela "desapareça" e o 'Indutor de Atividade' não se de conta que está realmente lendo os conteúdos.

\section{Resultados}

Os resultados iniciais obtidos através da pesquisa permitem perceber que à composiçáo tipográfica pode ajudar na construção das interfaces que e auxilia ao 'Indutor de Atividade' perceber o conteúdo exposto, já que permitiu perceber quais morfologias e quais tipos se saem melhor em cada uma das interfaces. Foi percebido também que quando se estuda tipografia para determinado suporte, deve ser levado em conta algumas características desse suporte que tem ou não, relação direta com a tipografia, como a qualidade de imagem e o tipo de aparelho e até o contexto de uso, ou seja, tanto as características técnicas, quanto as culturais daquele dispositivo influenciam em como ele é percebido, assim mudam como seu conteúdo deve ser tratado, o desafio é encontrar tipos que se sobressaem nos dois suportes conferindo uma identidade visual ao programa. Nesse sentido verificou que a percepçâo dos conteúdos pode ser facilitada quando se aplica uma tipografia que permite que as informaçóes sejam absorvidas mais naturalmente, e que a leiturabilidade e a legibilidade devam ser levadas em consideração para que o 'Indutor de Atividade' não se dê conta que está realmente lendo, nesse sentido, a informação também deve ser aplicada de forma objetiva e permitir que sua composição tanto através de animaçóes quanto de interaçóes aconteça harmoniosamente com o programa que se está assistindo, criando um cenário ideal para estimular o 'Indutor de Atividade' a perceber aquele conteúdo.

\section{Considerações Finais}

Percebeu-se que a tipografia pode ampliar as possibilidades de informação e composição de conteúdo, viabilizando a criação de interfaces naturais, fluidas e transparentes, essas características fazem com que as relações estabelecidas entre homem e computador sejam desfrutadas plenamente. Consequentemente ao dominar as regras clássicas tipográficas, atentando as características dos dispositivos que compóe a TVDi, possibilita ampliar a capacidades do 'Indutor de Atividade' absorver os conteúdos apresentados. Dessa forma, percebeu-se que o domínio dos mecanismos, requisitos e ferramentas, tanto da tipografia quanto da televisão digital permite que haja maior liberdade na criação de conteúdos para essa mídia. Também constatou-se a necessidade de traçar as características tipográficas mais adequadas aos smartphones, pois esses aparelhos 
têm telas menores com outras dinâmicas de informação interação e composição.

\section{Referências}

Barbalho, T. R.; Bezerra, E. P. (2014). Um jogo social para TV digital interativa. Revista Temática. Retrieved from: http://periodicos. ufpb.br/ojs/index.php/tematica/article/view/18812/10516

BBC. (2006). Interactive Television Design. Retrieved from: http:// www.bbc.co.uk/guidelines/futuremedia/desed/itv/ itv_design_v1_2006.pdf.

Bringhurst, R. (2005). Elementos do Estilo Tipográfico. São Paulo: Cosac Naify.

Cannito, N. G. (2009). A Televisão na Era Digital. Dissertação (doutorado) Escola de Comunicação e Artes/USP. São Paulo. Retrieved from: http://www.pos.eca.usp.br/sites/default/files/ file/ bdt/2009/2009-do-cannito_newton.pdf.

Cardoso. F. (2013) 2TV - Aplicativo de Segunda Tela para Dispositivos Móveis Retrieved from: http://portalintercom. org. br/anais/sudeste2013/resumos/R38-1785-1.pdf

Ciuccio, C. D.; Damacena, C. G.; Junior, I. A.; Leal, A. H.; Palos, K. I.; Santos, J.; Scholz, S. R.; Watanabe, T. T. (2013) Programa Piloto: Pense Nisso. São Paulo: Universidade Anhembi Morumbi.

Crocomo, F. A. (2007). TV Digital e a Produção Interativa: a comunidade manda notícias. Florianópolis: Editora da UFSC.

Esteves, R. (2010). O design brasileiro de tipos digitais: a configuração de um campo profissional. São Paulo: Blucher.

Farias, P. (2001). Tipografia digital. O impacto das novas tecnologias. Rio de Janeiro: $2 \mathrm{AB}$.

Higounet, C. (2004). História Concisa da Escrita. São Paulo: Parábola Editorial.

Hochuli, J. (2013). O Detalhe da Tipografia. São Paulo: WMF Martins fontes.

Lupton, E. (2006). Pensar com Tipos. São Paulo: Cosac Naify.
Marshall, L.; Meachem L. (2012). Cómo Utilizar la Tipografía. Hong Kong: Brume.

Miranda, J. B. (1998) Da interactividade. Crítica da nova mimesis tecnológica. In: GIANNETTI, C. (org.) Telemática: telecomunicaçáo, internet e ciberespaço (pp.119-128). Lisboa, LIS: Relógio D’Água.

Pagani, M. (2003). Multimedia and Interactive Digital TV: Managing the Opportunities Created by Digital Convergence. Hershey: IRM Press.

Pereira, A. D’a. (2007). Tipos: desenhos e utilização de letras no projeto gráfico. Rio de Janeiro: Quartet.

Perrotta, I. (2005). Tipos e Grafias. Rio de Janeiro: Senac Rio.

Pring, R. (2000). www.tipografia, 300 diseños tipográficos para sítios web. Barcelona: Custavo Gili.

Schlittler, J. P. A. (2012). TV digital interativa: convergência das mídias e interfaces do usuário. São Paulo: Blucher.

Spiekermann, E. (2011). A linguagem Invisível da Tipografia. São Paulo: Blucher.

Squirra, S.; Becker, V. (2009). TV Digital.Br: Conceitos e Estudos sobre ISDB-Tb. SP, Cotia: Ateliê Editorial.

Tubaro, A.; Tubaro, I. (1992). Tipografia, estudios e investigaciones sobre la forma de la escritura y del estilo de impresión. Buenos Aires: Universidade de Palermo/ Livraria Técnica CP67.

Willis, N.; Adams, V.; Sorkin, E.; Pagura, J.; Martin, B.; Crossland, D.; Skala, M.; Brilliant, M. (2014). Design With FontForge: A Book About How to Design New Typefaces with FontForge. Retrieved from: http://designwithfontforge.com/ en-US/ index.html.

Veiga, E. G.(2006). Modelo de Processo de Desenvolvimento de Programas para TV Digital e Interativa. Dissertação (mestrado) Curso de Mestrado Profissional em Redes de Computadores do Programa de Pós-graduação em Redes de Computadores / Universidade Salvador. Bahia. Retrieved from: http://tatiana .lavid.ufpb.br/wp-content/uploads/2012/03/dissetacao_elba.pdf. 